\title{
ASPEK KEPASTIAN HUKUM PENDIRIAN PERSEROAN UMK MENURUT UU NO.11 TAHUN 2020 TENTANG CIPTA KERJA
}

\author{
Marcelino Dennis Lesmana ${ }^{1}$, Nelssen Alessandro ${ }^{2}$, Sancarlous $^{3}$, Yuwono Prianto ${ }^{4}$ \\ ${ }^{1}$ Jurusan Ilmu Hukum, Universitas Tarumanagara Jakarta \\ E-mail: marcelino.205210144@stu.untar.ac.id) \\ ${ }^{2}$ Jurusan Ilmu Hukum, Universitas Tarumanagara Jakarta \\ E-mail:nelssen.205210128@stu.untar.ac.id \\ ${ }^{3}$ Jurusan Ilmu Hukum, Universitas Tarumanagara Jakarta \\ E-mail:sancarlous.205210127@stu.untar.ac.id \\ ${ }^{4}$ Hukum Universitas Tarumanagara, Magister Hukum pada Fakultas Hukum Universitas Tarumanagara. \\ E-mail : yuwonop@fh.untar.ac.id
}

\begin{abstract}
Law number 11 of 2020 concerning Job Creation has been inaugurated by the DPR together with the President, after the Law on Job Creation was enacted it caused a lot of controversy in the community where changes to Law number 40 of 2007 concerning Limited Liability Companies and Law number 20 of 20202008 concerning Micro, Small, and Medium Enterprises as well as regulations regarding the establishment of New Companies, namely Micro and Small Companies. The object of this research is the legal certainty of Micro, Small and Medium Enterprises Companies established under Law number 11 of 2020 concerning Job Creation. In this study using a normative type of research with a Legislation approach and a conceptual approach, this research shows the legal certainty of Micro and Small Companies established based on a statement in Indonesian based on Law number 11 of 2020 concerning Job Creation. One-sided legal actions are legal actions carried out by one party only and give rise to rights and obligations by one party, while two-party legal actions are legal actions carried out by two parties and give rise to rights and obligations for both parties involved. In this research journal aims to inform the public about the difference between a MSE company and a limited liability company. To establish a business, it does not have to be established by two people, but only one person can establish a UMK company but the legal certainty of a MSE company is still weak compared to other limited liability companies
\end{abstract}

Keywords : job creation, legal certainty, micro and small business companies.

ABSTRAK
Undang-Undang nomor 11 Tahun 2020 tentang Cipta Kerja telah diresmikan oleh DPR bersama Presiden, setelah Undang-Undang Cipta Kerja ini diresmikan banyak menimbulkan kontraversi di masyarakat dimana perubahan terhadap Undang-Undang nomor 40 Tahun 2007 tentang Perseroan Terbatas dan Undang-Undang nomor 20 tahun 2008 membahas tentang Usaha Mikro, kecil, dan menengah serta pengaturan tentang pendirian Perseroan Baru yaitu Perseroan Mikro Dan Kecil objek penelitian ini adalah kepastian hukum Perseroan Usaha Mikro Kecil yang didirikan berdasarkan Undang-Undang nomor 11 Tahun 2020 tentang Cipta Kerja. Dalam penelitian ini menggunakan jenis penelitian normatif dengan pendekatan Peraturan Perundang-Undangan dan pendekataan konseptual, penelitian ini menunjukkan kepastian hukum Peseroan Mikro dan Kecil yang didirikan berdasarkan surat pernyataan dalam Bahasa Indonesia berdasarkan Undang-Undang nomor 11 Tahun 2020 tentang Cipta Kerja. Perbuatan hukum sepihak, adalah perbuatan hukum yang dilakukan oleh satu pihak saja dan menimbulkan hak dan kewajiban oleh satu pihak pula, sedangkan Perbuatan hukum dua pihak, adalah perbuatan hukum yang dilakukan oleh dua pihak dan menimbulkan hak-hak dan kewajiban-kewajiban bagi kedua pihak yang menimbulkan hubungan (timbal-balik).Dalam jurnal penelitian ini bertujuan untuk memberitahukan kepada masyarakat tentang perbedaan perseroan UMK dan perseroan terbatas untuk mendirikan suatu usaha tidak harus didirikan oleh dua orang melainkan satu orang saja sudah bisa mendirikan perseroan UMK tetapi perseroan UMK kepastian hukumnya masih lemah dibandingkan dengan perseroan terbatas lainnya.

Kata Kunci: cipta kerja; kepastian hukum; perseroan usaha mikro dan kecil.

\section{PENDAHULUAN}

\section{Latar Belakang}

Untuk mengetahui definisi perseroan, ketentuan biaya dalam perseroan, syarat perseroan agar dapat memenuhi usaha mikro dan kecil, bagaimana surat pernyataan pendirian perseroan, 
ketentuan lebih lanjut mengenai pendirian perseroan, bagaimaana perseroan dapatdidirikan, pengambilan bagian saham pada saat perseroan didirikan, peleburan suatu perseroan, perseroanmendapat status sebagai badan hukum, pengalihan saham kepada orang lain atau perseroanmengeluarkan mengeluarkan saham baru kepada orang lain, tanggung jawab pribadi pemegang saham, Ketentuan yang tidak berlaku untuk mewajibkan Perseroan, ketentuan yang mewajibkan suatu perseroan didirikan. Maka berikut ini akan kami paparkan arti serta maksud dari pada hal- hal yang penulis sampaikan diawal. Perseroan memiliki pengertian yaitu, perserikatan dagang. Ketentuan mengenai biaya perseroan diatur dalam pasal 153 Undang Undang cipta tenaga kerja (ciptaker) yang berisi "Ketentuan mengenai biaya Perseroan sebagai badan hukum diatur sesuai dengan ketentuan di bidang penerimaan negara bukan pajak". Syarat perseroan untuk dapat memenuhi usaha mikro dan kecil adalah hanya dapat didirikan oleh satu orang saja. Sebagaimana diatur dalam Undang - Undang Cipta Tenaga Kerja (ciptaker) pasal $153 \mathrm{~A}$ ayat 1 yang berisi "Perseroan yang memenuhi kriteria Usaha Mikro dan kecil hanya dapat didirikan oleh satu (1) orang”. Surat pendirian perseroan diatur dalam Undang - Undang Cipta Tenaga Kerja (ciptaker) pasal 153A ayat 2 yang berisi "Pendirian perseroan untuk usaha mikro dan kecil sebagaimana dimaksusd dalam ayat 1 dilakukan berdasarkan surat pernyataan pendirian yang dibuat dalam Bahasa Indonesia". Ketentuan lebih lanjut mengenai perseroan diatur dalam Undang - Undang Tenaga Kerja (ciptaker) pasal 153A ayat 3 yang berisi "Ketentuan lebih lanjut mengenai Pendirian Perseroan untuk usaha Mikro dan Kecil diatur dalam peraturan Pemerintah". Perseroan didirikan oleh dua (2) orang atau lebih melalui akta notaris sebagaimana diatur dalam Undang - Undang Perseroan Terbatas nomor 40 tahun 2007 pasal 7 ayat 1 yang berisi "Perseroan didirikan oleh 2 (dua) orang atau lebih dengan akta notaris yang dibuat dalam Bahasa Indonesia". Pengambilan bagian saham pada saat perseroan didirikan diatur dalam Undang - Undang Perseroan Terbatas nomor 40 tahun 2007 pasal 7 ayat 2 yang berisi 'Setiap pendiri Perseroan wajib mnegambil bagian saham pada saat perseroan didirikan'.

Peleburan suatu perseroan diatur dalam Undang - Undang Perseroan Terbatas nomor 40 tahun 2007 pasal 7 ayat 3 yang berisi "Ketentuan sebagaimana dimaksud pada ayat 2 tidak berlaku dalam rangka peleburan". Perseroan mendapat status sebagai badan hukum daitur dalam Undang - Undang Perseroan Terbatas nomor 40 tahun 2007 pasal 7 ayat 4 yang berisi "Perseroan memperoleh status badan hukum pada tangggal diterbitkannya keputusan menteri pada tanggal diterbitkannya keputusan menteri mengenai keputusan hukum mengenai pengesahan badan hukum perseroan". Pembagian saham kepada orang lain atau Perseroan mengeluarkan saham baru kepada orang lain diatur dalam Undang - Undang Perseroan Terbatas 40 tahun 2007 pasal 7 ayat 5 . Tanggungjawab pribadi seorang pemegang saham diatur dalam Undang-Undang Perseroan Terbatas nomor 40tahun 2007 pasal 7 ayat 6 yang berisi "Dalam hal jangka waktusebagaimana dimaksud dalam pasal 5 telah dilampui, pemegang saham tetap kurang dari 2 orang, pemegang saham bertanggung jawab secara pribadi atas segala perikatan dan kerugian Perseroan, dan atas peromohonan pihak yang bekepentingan, pengadilan negeri dapat membubarkan Perseroan tersebut". Ketentuan mendirikan perseroan diatur dalam Undang Undang Perseroan Terbatas nomor 40 tahun 2007 pasal 7 ayat 7 yang berisi tentang "Ketentuan yang mewajibkan perseroan didirikan oleh 2 orang atau lebih sebagaimana dimaksud pada ayat 1 dan ketentuan pada ayat 5, serta ayat 6 tidak berlaku bagi: a) Persero yang seluruh sahamnya tidak dimiliki negara. b) Perseroan yang mengelola bursa efek, kliring dan penjaminan, lembaga penyimpangan dan penyelesaian, dan lembaga lain sebagaimana diatur dalam Undang - Undang PasarModal. Dalam jurnal penelitian ini bertujuan untuk memberitahukan kepada masyarakat tentang perbedaan perseroan UMK dan perseroan terbatas untuk mendirikan suatu usaha tidak harus didirikan oleh dua orang melainkan satu orang saja sudah bisa mendirikan perseroan UMK tetapi perseroan UMK kepastian hukumnya masih lemah dibandingkan dengan perseroan terbatas lainnya. 


\section{Rumusan Masalah}

Bagaimana aspek kepastian hukum pendirian perseroan UMK yang dilakukan berdasarkan surat pernyataan dalam Bahasa Indonesia ditinjau dari Undang-Undang No.11 Tahun 2020 Tentang Cipta Kerja.

\section{METODE PENELITIAN}

Penulis menggunakan metode penelitian normatif dan konseptual, penelitian ini mengkaji kepastian hukum berdasarkan Perundang-undangan dan mengkonsep data yang berkaitan dengan pendirian perseroan. Penulis dalam penelitian ini memberikan pembahasan kepastian hukum terhadap pendirian Perseroan UMKdi masyarakat Indonesia.

\section{HASIL DAN PEMBAHASAN}

Undang-Undang nomor 11 Tahun 2020 tentang Cipta Kerja meurpakan sumber penting dalam penelitian ini dan menggunakan Undang-Undang nomor 40 Tahun 2007 tentang Perseroan Terbatas sebagai perbandingan kepastian hukum. Cipta Kerja adalah upaya pemerintah untuk menciptakan lapangan pekerjaan melalui usaha pemerdayaan koperasi, UMKM, peningkatan investasi dan memberikan suatu kemudahan dalam berusaha serta memepercepat proyek yang strategis.

Perseroan Terbatas secara umum adalah badan usaha yang berbadan hukum yang didirikan berdasarkan surat perjanjian yang diatur dalam Undang-Undang Nomor 40 Tahun 2007, dalam suatu kegiatan usaha memiliki modal yang berupa saham dalam suatu usaha. Usaha Mikro, Kecil, dan Menengah yang selanjutnya disingkat UMKM adalah usaha mikro, usaha kecil, dan usaha menengah sebagaimana dimaksud dalam Undang-Undang tentang Usaha Mikro, Kecil, dan Menengah.Pendirian Perseroan UMKM ada beberapa syarat yang tercantum dalam pasal 153A Undang-Undang Cipta Kerja ayat 1-3 di antaranya "1.Perseroan yang memenuhi kriteria usaha mikro dan kecil dapat didirikan oleh 1 (satu) orang atau lebih. 2. Pendirian Perseroan untuk Usaha Mikro dan Kecil sebagaimana dimaksud pada ayat (1) dilakukan berdasarkan surat pernyataan pendirian yang dibuat dalam Bahasa Indonesia. 3. Ketentuan lebih lanjut mengenai pendirian Perseroan untuk Usaha Mikro dan Kecil diatur dalam Peraturan Pemerintah."Kepastian hukum perseroan UMK dapat dilihat dari syarat pendirian perseroan UMK yang sebagaimana dimaksud dalam pasal 153A ayat 2 Undang-Undang

Cipta Kerja yang berbunyi "Pendirian Perseroan untuk Usaha Mikro dan Kecil sebagaimana dimaksud pada ayat (1) dilakukan berdasarkan surat pernyataan pendirian yang dibuat dalam Bahasa Indonesia".

Perseroan UMK ini memiliki perbedaan dengan Perseroan Terbatas yang pada umumnya pendiriannya harus menggunakan akta Notaris menurut Undang-Undang No.40 Tahun 2007 tentangPerseroan terbatas, tetapi bagi perseroan UMK itu tidak berlaku yang dimana syarat pendiriannya hanya 1 orang saja sudah bisa mendirikan perseroan UMK dan tidak perlu Akta Notaris tetapi dibuat dalam surat pernyataan dalam bahasa Indonesia (Di Bawah Tangan), dimana disini memiliki permasalahan atas pada pendiri dan pemegang saham pada perseoran mikro dan kecil hanya satu orang maka akan sulit untuk menentukan tolak ukur tanggung jawab berdirinya perseroan,karena tanggung jawabnya hanya sebatas modal yang dimiliki dalam perseroan,perseroan mikro dan kecil kesulitan untuk menjalankan program perseroan yaitu dimana sudah diatur dalam RUPS pada pasal 86 ayat 1 Undang-Undang NO.40 Tahun 2007 tentang Perseroan Terbatas yang berbunyi "RUPS dapat dilangsungkan jika dalam RUPS lebih dari 1/2 (satu perdua) bagian dari jumlah seluruh saham dengan hak suara hadir atau diwakili, kecuali undang-undang dan/atau anggaran dasar menentukan jumlah kuorum yang lebih besar" 
dilihat dari Umdang-Undang No.11 Tahun 2020 Tentang Cipta Kerja dan Undang-Undang No.40 Tahun 2007 Tentang perseroan terbatas memiliki banyak perbedaan dalam segi prinsip.

Perseroan UMK memiliki kepastian hukum yang lebih lemah karena aspek serta struktur hukum dalam Perseroan Terbatas lebih kuat hal itu dibuktikan karena Perseroan Terbatas (PT) merupakan badan hukum yang ditetapkan langsung oleh KEMENKUMHAM sedangkan Usaha Mikro Kecil Menegah (UMKM) bukan merupakan badan hukum. Perizinan UMK meliputi izin usaha,bukti pendaftaran dan tanda bukti pendataan.

Usaha mikro dan kecil memiliki suatu criteria yang bentuknya harus dirubah sesuai dengan peraturan perundang-undangan yang berlaku di Indonesia yaitu Undang-Undang Nomor 40 Tahun2007 Tentang Perseroan Terbatas. Jadi, apabila pengklasifikasian kriteria usaha dalam Undang-Undang UMKM dirubah dan tidak ada pengklasifikasian kriteria usaha, dan ketentuan lebih lanjut diatur di dalam Peraturan Pemerintah maka akan terjadi kekosongan hukum dan tidak dapatmenerapkan UU Cipta Kerja yang berkaitan dengan perseroan mikro dan kecil terutama yangterdapat pada Pasal $153 \mathrm{H}$.

Jika membedakan suatu peristiwa hukum kapan harus dibuat akta pihak dan kapan harus dibuat akta berita acara maka diperlukan kembali melihat fakta hukum yangmerujuk pada tindakan/ perbuatan hukum. Perbuatan hukum ini dibedakan menjadi 2 (dua) yaitu perbuatan hukum sepihak (wasiat, pengakuan anak luar kawin, penolakan harta peninggalan) danperbuatan hukum berganda (keputusan rapat). Perbuatan hukum sepihak merupakan suatu perbuatan hukum yang dilakukan oleh satu orang dan menimbulkan yang namanya hak dan kewajiban oleh satu orang juga, sedangkan Perbuatan hukum dua pihak, adalah suatu perbuatan hukum yang dilakukan oleh dua pihak dan menimbulkan suatu hak-hak dan kewajiban-kewajiban bagi kedua pihak sehingga menimbulkan hubungan (timbal-balik).

\section{KESIMPULAN DAN SARAN}

Undang - Undang nomor 11 tahun 2020 mengenai Cipta Kerja menyatakan bahwa pendirian perseroan usaha mikro dan kecil dapat didirikan oleh satu orang dan surat pernyataan pendirian harus berbahasa Indonesia, Perseroan Usaha Mikro dan Kecil bukan merupakan persekutuan karena pendiriannya tidak dilakukan oleh dua orang atau lebih, Perseroan Usaha Mikro dan Kecil hanya diririkan oleh satu orang, Kitab Undang - Undang

Hukum Dagang dan Undang - Undang Nomor 40 tahun 2007 tentang Perseroan Terbatas menyatakan bahwa landasan Yuridis dalam pendirian Perseroan merupakan persekutuan. Syarat - Syarat pendirian Perseroan UMKM tercantum dalam pasal 153A Undang - Undang Cipta Tenaga Kerja ayat 1 sampai dengan 3, Undang - Undang Perseroan Terbatas nomor 40 tahun 2007 pasal 86 ayat 1 menyatakan bahwa 'Rapat Umum Pemegang Saham (RUPS) dapat dilaksanakan lebih dari $1 / 2$ bagian dari jumlah seluruh saham dengan hak suara hadir diwakili, kecuali undang - undang dan / atau anggaran dasar (ad) menentukan jumlah kuorum yang lebih besar, Rapat Umum Pemegang Saham (RUPS) adalah rapat bagi para Pemegang Saham untuk mengambil keputusan penting yang kewenangannya dalam anggaran dasar dan peraturan perundang-undangan yang berlaku, Definisi dari Perseroan adalah perserikatan dagang, Definisi akta notaris menurut Herzien Inlandsch Reglement (HIR) dan Kitab Undang - Undang Hukum Perdata (KUHPER) adalah dokumen resmi yang dikeluarkan oleh notaris yang mempunyai pembuktian mutlak dan mengikat, Cipta Kerja adalah upaya penciptaan kerja melalui usaha kemudahan, perlindungan, dan pemberdayaan koperasi dan usaha mikro, kecil, dan menengah, peningkatan ekosistem investasi dan kemudahan berusaha, dan investasi Pemerintah Pusat dan percepatan proyek strategis nasional.

Saran kami adalah seharusnya pemerintah mengatur dengan jelas bentuk Perseroan Mikro Kecil supaya legalitas Perseroan Mikro dan kecil menjadi jelas tatacara pendirian beserta kedudukannya.Dan juga ketentuan - ketentuan yang bersifat mengatur harus dipenuhi sehingga 


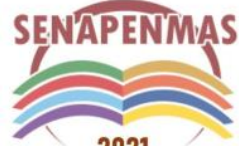

2021
Seminar Nasional Hasil Penelitian dan Pengabdian Kepada Masyarakat 2021

Pengembangan Ekonomi Bangsa Melalui Inovasi Digital Hasil Penelitian dan Pengabdian Kepada Masyarakat Jakarta, 21 Oktober 2021

bentuk khusus dari Perseroan Terbatas yaitu Perseroan Kecil menjadi lebih jelas. Pemerintah juga harus lebih mengoptimalkan pengawasan terhadap Perseroan Mikro dan Kecil agar menjamin perlindungan hukum pada para pihak yang berhubungan dengan Perseroan Mikro dan Kecil.

\section{Ucapan Terima Kasih}

Segala puji dan syukur kehadirat Tuhan Yang Maha Esa,atas berkat dan rahmat-Nya sehingga kami selaku Tim penulisdapat menyelesaikan artikel yang berjudul Aspek Kepastian Hukum Pendirian Perseroan UMK Menurut UU NO. 11 Tahun 2020 Tentang Cipta Kerja. Kami jugaberterima kasih kepada Senapenmas seminarnasional yang telah mengadakan acara ini dan kami juga sangat berterima kasih kepada Universitas Tarumanagara selaku penyelenggara acara ini dan Universitas lainnya yang ikut serta dalam acara ini dan kami juga berterima kasih kepada panitia Senapenmas.

\section{REFERENSI}

Indonesia, Undang-Undang Nomor 11 tahun 2020 Tentang Cipta Kerja, Pasal 153A.

Agustinus Haryono,"Mengenal Perseroan Terbatas", diakses 11 September 20121 dari www.icopi.or.id.

Indonesia, Undang-Undang Nomor 40 tahun 2007 Tentang Cipta Kerja Perseroan Terbatas, Pasal 7.

R.Soeroso,'A Arti Perbuatan Hukum Bukan Perbuatan Hukum dan Akibat Hukum", diakses 11 September 2021 dari www. jamkridabanten.co.id. 
Seminar Nasional Hasil Penelitian dan Pengabdian Kepada Masyarakat 2021

Pengembangan Ekonomi Bangsa Melalui Inovasi Digital Hasil Penelitian dan

Pengabdian Kepada Masyarakat

Jakarta, 21 Oktober 2021

(halaman kosong) 